\title{
Cloned Bacillus subtilis Chromosomal DNA Mediates Tetracycline Resistance When Present in Multiple Copies
}

\author{
CATHERINE L. IVES AND KENNETH F. BOTT* \\ Department of Microbiology and Immunology, University of North Carolina at Chapel Hill, \\ Chapel Hill, North Carolina 27599
}

Received 9 September 1988/Accepted 13 December 1988

\begin{abstract}
Plasmid pCIS7, containing 11.5 kilobases (kb) of Bacillus subtilis DNA, was isolated from a Tn917 transposon insertion in tetracycline-sensitive $B$. subtilis KS162. When integrated into the chromosome of $B$. subtilis 168, this plasmid conferred tetracycline resistance upon reiteration of the plasmid DNA sequences in the chromosome. Deletions and subclones of pCIS7 were constructed and introduced into an Escherichia coli in vitro transcription-translation system. A 72-kilodalton protein was localized to a 3.1-kb PstI-EcoRI fragment of the plasmid. Amplification of the 3.1-kb PstI-EcoRI fragment was required for expression of tetracycline resistance in $B$. subtilis 168 . By hybridization to previously characterized clones, the 11.5-kb fragment was localized to the origin region of the chromosome. Through contour-clamped homogeneous electric field electrophoresis, this cluster of clones was shown to reside on a 200-kb NotI fragment bridging $S$ fiI fragments of 150 and $250 \mathrm{~kb}$ and was oriented with respect to the purA and guaA loci, developing an accurate physical map of the region surrounding the origin of replication.
\end{abstract}

Plasmids that confer resistance to tetracycline have been found in a wide range of bacterial species. It has been suggested that plasmid-mediated tetracycline resistance $\left(\mathrm{Tet}^{\mathrm{r}}\right)$ in clinical isolates originated from soil organisms sharing the same habitat as streptomycetes, which synthesize the antibiotic (4). In members of the family Enterobacteriaceae, plasmid determinants encoding $\operatorname{Tet}^{\mathrm{r}}$ make up five separate but related groups, tetA through tetE (20). DNA sequence analyses indicate that they probably evolved from a common origin $(16,39)$. Genes tet $A$ through tet $D$ encode membrane proteins of similar size (43 kilodaltons [kDa]) which are involved in energy-dependent efflux of tetracycline from the cell (21). In gram-positive streptococci, four Tet $^{\mathrm{r}}$ determinants, tet $L$, tet $M$, tet $N$, and tet $O$, have been studied in some detail $(3,10,20,21)$. TetL appears to mediate $\operatorname{Tet}^{r}$ through a membrane efflux, whereas TetM, TetN, and TetO encode cytoplasmic proteins which presumably protect ribosomes from inhibition by tetracycline. Unlike the gram-negative $\mathrm{Tet}^{\mathrm{r}}$ determinants, TetO is a protein of $72 \mathrm{kDa}(3,6,19,35 \mathrm{a})$.

In Bacillus spp., several independent chromosomally mediated $\mathrm{Tet}^{\mathrm{r}}$ determinants have been reported (28). Shishido et al. (32) showed that protoplasts of a tetracycline-sensitive $\left(\mathrm{Tet}^{\mathrm{s}}\right)$ strain could be regenerated on tetracycline-containing media. In the presence of exogenous DNA, this process apparently stimulated excision of an autonomously replicating $\operatorname{Tet}^{\mathrm{r}}$ DNA fragment which bore no resemblance to the exogenous plasmid. The recovered DNA was identical to pBC16, a Tet ${ }^{\mathrm{r}}$ plasmid independently isolated from Bacillus cereus (1). Wilson and Morgan described endogenous gene amplifications from regenerated protoplasts associated with Tet $^{r}$ but without addition of exogenous DNA (41). Williams and Smith defined the tetB mutation isolated after ethyl methanesulfonate mutagenesis (40) and postulated that $\mathrm{Tet}^{\mathrm{r}}$ was mediated by an alteration in the membrane, since no difference in ribosomal proteins could be detected by twodimensional gel electrophoresis.

In the latter two cases $(40,41), \operatorname{Tet}^{\mathrm{r}}$ was genetically

* Corresponding author. mapped near the origin of replication. No functional origin has been isolated from Bacillus subtilis, and the genetic linkage data between loci in this region is ambiguous because unknown experimental complications make the data from reciprocal crosses inconsistent $(36,42)$. Therefore; physical characterization of DNA from the origin region is essential in understanding the regulation of cellular functions.

We have identified a chromosomal fragment isolated from the origin region of the $B$. subtilis chromosome, not capable of autonomous replication, which mediates Tet $^{\mathrm{r}}$ when amplified. The amplification phenomenon suggests a need for increased gene dosage for expression of $\operatorname{Tet}^{\mathrm{r}}$. Deletions and subclones of this DNA were tested for the ability to confer $\mathrm{Tet}^{\mathrm{r}}$ in Escherichia coli and B. subtilis. Plasmid pCIS7 encodes a $72-\mathrm{kDa}$ protein, as determined by in vitro transcription-translation analysis. Through hybridization to previously characterized clones, this DNA was oriented to the origin-associated loci, which resulted in an accurate physical map of that chromosomal region.

\section{MATERIALS AND METHODS}

Bacterial strains and plasmids. Bacterial strains and plasmids used in this study are described in Tables 1 and 2, respectively.

Media, chemicals, and enzymes. Tryptose blood agar base (TBAB), tryptic soy broth, and Penassay broth were obtained from Difco Laboratories, (Detroit, Mich.). Luria broth (LB) is $10 \mathrm{~g}$ of tryptone, $5 \mathrm{~g}$ of yeast extract, and $10 \mathrm{~g}$ of sodium chloride per liter. Ampicillin, chloramphenicol, and tetracycline were purchased from Sigma Chemical Co. (St. Louis, Mo.) and used at concentrations of 50, 5, and 20 $\mu \mathrm{g} / \mathrm{ml}$, respectively, unless otherwise stated. All other chemicals were purchased from Sigma. Restriction enzymes were obtained from Bethesda Research Laboratories, Inc. (Gaithersburg, Md.), International Biotechnology Inc., and New England BioLabs, Inc. (Beverly, Mass.). T4 DNA ligase and $E$. coli DNA polymerase were purchased from International Biotechnology Inc. All enzymes were used according to the instructions of the manufacturer. $\left[\alpha{ }^{32} \mathrm{P}\right] \mathrm{dCTP}$ was purchased from Dupont, NEN Research Products (Boston, 
TABLE 1. Bacterial strains

\begin{tabular}{|c|c|c|}
\hline Bacterium & $\begin{array}{l}\text { Relevant genotype } \\
\text { or phenotype }\end{array}$ & Source \\
\hline E. coli $\mathrm{HB} 101$ & $\operatorname{rec} A$ & G. Rapaport \\
\hline \multicolumn{3}{|l|}{ B. subtilis } \\
\hline 168 & $\operatorname{trpC} 2$ & \\
\hline Kit1 & purA cysA trpC2 & R. Dedonder (7) \\
\hline JH858 & guaA cys $A$ & J. Hoch \\
\hline KS162 & Tn917 (Erm) & K. Sandman (29) \\
\hline $168(\mathrm{pCIS} 7)$ & Cat Tet & This study \\
\hline $168 \mathrm{Nov}$ & Nov & Sugino and Bott (36) \\
\hline $168 \operatorname{Nov}(p C I S 7)$ & Nov Cat Tet & This study \\
\hline RAD1 & Tet & Wilson and Morgan (41) \\
\hline
\end{tabular}

Mass.). Translation-grade $\left[{ }^{35} \mathrm{~S}\right]$ methionine was purchased from ICN Biomedicals, Inc. (Irvine, Calif.). Endonuclease restriction digests were analyzed by electrophoresis in horizontal 0.7 or $1.0 \%$ agarose gels in Tris-acetate buffer $(40 \mathrm{mM}$ Tris [pH 8.0], $20 \mathrm{mM}$ sodium acetate, $2.5 \mathrm{mM}$ EDTA disodium). InCert agarose was purchased from FMC Corp., (Rockland, Maine).

DNA isolation. Small-scale plasmid lysates from $E$. coli were prepared according to the method of Holmes and Quigley (14). Large-scale preparations were done according to a modified version of the procedure of Norgard (23), using $1 \%$ sodium dodecyl sulfate for lysis instead of sodium deoxycholate and Brij 58, or by the alkaline lysis procedure outlined in the Promega Biotech GemSeq K/RT sequencing system technical manual (1986). Plasmids pCIS7 and pCIS2 were excised from the chromosome of $B$. subtilis KS162, carrying Tn917, by the method of Youngman et al. (45). Briefly, integrative plasmid vectors pTV20 and pTV21 22 were linearized with $P v u I I$ and transformed into $B$. subtilis KS162. Through marker replacement with homologous Tn917 sequences, chloramphenicol acetyltransferase-resistant $\left(\mathrm{Cat}^{\mathrm{r}}\right)$ transformants were obtained. DNA from these transformants was digested with $S p h I$ and religated in dilute solution. The DNA was transformed into competent $E$. coli HB101, and transformants were selected on LB medium containing ampicillin. By using pTV20 and pTV21 22 , DNA on both sides of the transposon insertion was cloned.

Chromosomal DNA was isolated from Bacillus cells growing exponentially in Penassay broth according to the method of Saito and Miura (26) and purified on an equilibrium $\mathrm{CsCl}$ gradient or by the protoplast lysis procedure of Wilson and Morgan (41). DNA used for contour-clamped homogeneous electric field (CHEF) electrophoresis was prepared by a modification of the method of Schwartz and Cantor for DNA isolation for pulse-field gel electrophoresis (31). An over- night culture was used to inoculate $25 \mathrm{ml}$ of Penassay broth to an optical density at $600 \mathrm{~nm}$ of approximately 0.1 . This culture was grown at $37^{\circ} \mathrm{C}$ to an optical density at $600 \mathrm{~nm}$ of $0.8 ; 5 \mathrm{ml}$ was centrifuged at $3,000 \times g$ for $10 \mathrm{~min}$, and the pellet was suspended in $1 \mathrm{ml}$ of SMMP buffer $(4 \times$ Penassay broth, $2 \times$ SMM [1 M sucrose, $0.04 \mathrm{M}$ malic acid, $0.04 \mathrm{M}$ $\left.\mathrm{MgCl}_{2}\right]$ ). Lysozyme was added to a final concentration of 2 $\mathrm{mg} / \mathrm{ml}$, and the mixture was incubated at $37^{\circ} \mathrm{C}$ for 30 to 60 min. The extent of protoplasting was examined under a phase-contrast microscope. A $1-\mathrm{ml}$ amount of $2 \%$ InCert agarose (FMC) was added; $100-\mu$ l portions were quickly dispensed into a Plexiglas (Rohm \& Haas Co., Philadelphia, Pa.) mold and chilled on ice. The blocks of immobilized protoplasts were added to lysis buffer $(6 \mathrm{M}$ Tris chloride $[\mathrm{pH}$ 7.6], $1 \mathrm{M} \mathrm{NaCl}, 100 \mathrm{mM}$ EDTA [pH 7.5], 0.5\% Brij 58, 0.2\% deoxycholate, $0.5 \%$ Sarkosyl [CIBA-GEIGY Corp., Summit, N.J.], $20 \mu \mathrm{g}$ of DNase-free RNase per $\mathrm{ml}, 1 \mathrm{mg}$ of lysozyme per ml) and incubated at $37^{\circ} \mathrm{C}$ for 14 to $18 \mathrm{~h}$ with gentle shaking. The blocks $(100-\mu l$ volume $)$ were then transferred to proteinase $\mathrm{K}$ buffer (0.5 M EDTA [pH 9.0], $1 \%$ Sarkosyl, $2 \mathrm{mg}$ of proteinase $\mathrm{K}$ per $\mathrm{ml}$ ), incubated at $50^{\circ} \mathrm{C}$ for 2 days with gentle shaking, and stored in $10 \mathrm{mM}$ Tris chloride ( $\mathrm{pH} 7.5)-0.1 \mathrm{mM}$ EDTA (TE) at $4^{\circ} \mathrm{C}$.

The blocks containing high-molecular-weight DNA were suitable as a source of DNA for transformation experiments (after brief exposure at $42^{\circ} \mathrm{C}$ to melt the agarose). By using this DNA, it was possible to demonstrate transformation linkage to markers not normally linked by using DNA purified by conventional means $(13,37)$.

For restriction digestions, one-half block was washed three times in $10 \mathrm{ml}$ of TE buffer and then washed twice in 1 $\mathrm{ml}$ of $1 \times$ restriction buffer at $37^{\circ} \mathrm{C}$ for $20 \mathrm{~min}$ with gentle shaking. Blocks were placed in $200 \mu \mathrm{g}$ of $1 \times$ restriction buffer, $100 \mathrm{U}$ of appropriate enzyme was added, and the blocks were incubated overnight.

Isolation of plasmid deletions, subclones, and recombinant bacteriophage. Deletions of pCIS7 (see Fig. 3) were constructed as follows. Plasmid DNA $(1 \mu \mathrm{g})$ was partially digested with HindIII or PstI. Digested DNA was extracted twice with phenol and once with chloroform, ethanol precipitated, and suspended in TE buffer. The digested DNA was religated with T4 DNA ligase and transformed into $E$. coli HB101, and transformants were selected on LB medium containing $50 \mu \mathrm{g}$ of ampicillin per ml. Plasmid DNA from these transformants was extracted and screened for deletions by agarose gel electrophoresis. The structures of the deleted plasmids were analyzed by restriction enzyme mapping, using EcoRI, PstI, SphI, and HindIII single and double digests.

TABLE 2. Plasmids

\begin{tabular}{|c|c|c|c|c|}
\hline Plasmid & $\begin{array}{l}\text { Selectable } \\
\text { marker(s) }\end{array}$ & Replication $^{\prime \prime}$ & Vector(s) & Source \\
\hline pCIS7 $^{b}$ & Tet $^{c}$ Cat Amp & $\mathrm{C}$ & pTV20 & This study \\
\hline pCIS2 & Cat Amp & $\mathrm{C}$ & pTV $21 \Delta 2$ & This study \\
\hline pTV20 & Cat Amp Erm & $\mathrm{C}+\mathrm{S}$ & & Youngman (45) \\
\hline pTV $21 \Delta 2$ & Cat Amp Erm & $C+S$ & & Youngman (45) \\
\hline pMS31 & Tet Cat & $\mathrm{C}$ & pJAB1 & Sargent and Bennett (30) \\
\hline pGEM-BLUE & Amp & $\mathrm{C}$ & & Promega Biotech \\
\hline pMI1101 & Cat Amp & $\mathrm{C}$ & pBR322, pC194 & M. Lampe \\
\hline pAK1 & Cat Amp & $\mathrm{C}$ & pBR322, pC194 & Lampe and Bott (18) \\
\hline
\end{tabular}

${ }^{a} \mathrm{C}$, Replication in $E$. coli; $\mathrm{S}$, replication in B. subtilis.

${ }^{b}$ Deletions and subclones of pCIS7 are described in the text and the legend to Fig. 3.

c Denotes Tet ${ }^{r}$ when pCIS7 is integrated and amplified in the $B$. subtilis chromosome. 


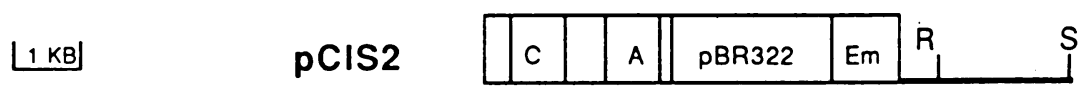

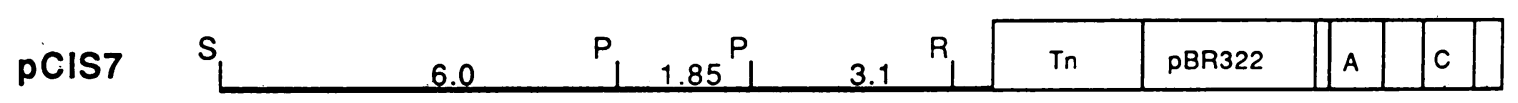

FIG. 1. Restriction maps of pCIS7 and pCIS2. Plasmids were constructed as described in the text. Vector DNA is indicated by a box; $B$. subtilis DNA is indicated by a bold line. Distances between cleavage sites are indicated in kilobases. Abbreviations: C, chloramphenicol acetyltransferase from pC194; A, $\beta$-lactamase gene of pBR322; Em, erythromycin resistance gene of Tn917; Tn, Tn917 DNA; S, SphI; P, PstI; R, EcoRI.

Subclones of pCIS7 (see Fig. 3) were constructed by random cloning of restriction enzyme fragments. Plasmid p6SP is the 6.0-kilobase (kb) SphI-PstI DNA fragment of pCIS7 constructed by separately digesting $1 \mu \mathrm{g}$ of pCIS7 and pGEM-BLUE (Promega Biotech) each with PstI. Digests were phenol extracted, chloroform extracted, ethanol precipitated, suspended in TE buffer, digested with SphI, and treatet as above. The PstI-SphI-digested plashids were resuspended in TE and thixed in $1 \times$ ligase buffer. T4 ligase was added, and the realtion mixture was incubatted for 2 to $4 \mathrm{~h}$ at room temperature. The ligations were then transformed into competent $E$. coli HB101. Transformants were screethed on LB medium containing ampicillin, IPTG (isopropyl- $\beta$-D-thiogalactopyranoside) and X-Gal (5-bromo-4chloro-3-indolyl- $\beta$-D-galactopyranoside) $(50 \mu \mathrm{g} / \mathrm{ml}$; Sigma). Potential subclones (white colonies) were analyzed by agarose gel electrophoresis. Plasmids pY4, pA25, and p4-9 were constructed in a similar manner, using Pst I and partial HindIII restriction digests. Plasmid pY4 contains the $1.8-\mathrm{kb}$ PstI fragment, pA25 contains the 1.8-kb HindIII fragment, and p4-9 contains three contiguous HindIII fragments of pCIS7.

A gram-positive selectable marker was cloned into p6SP, pY4, pA25, and p4-9 for assaying Tet $^{\mathrm{r}}$ in B. subtilis. Plasmid pMI1101, a vector containing a $\mathrm{Cat}^{\mathrm{r}}$ gene from pC194, was used (9). Plasmid DNA was digested with BamHI, liberating the Cat ${ }^{r}$ gene cassette; and fragments were randomly cloned into the unique BamHI site of the pGEM-BLUE subclones. The recovered clones were screened for ampicillin resistance $\left(\mathrm{Amp}^{\mathrm{r}}\right)$ and $\mathrm{Cat}^{\mathrm{r}}$ in $E$. coli, and their constructions were confirmed by restriction enzyme mapping.

Recombinant lambda phage F3 was isolated from a Charon 30 library after screening of plaque lifts by hybridization to radiolabeled pCIS7 (22). The library was constructed by cloning size-fractionated partial Sau3A digests of $B$. subtilis DNA into the BamHI site of the lambda vector.

Transformation. Plasmids were introduced into $E$. coli strains by the transformation procedure of Hanahan (12). $B$. subtilis was made competent by the method of Bott and Wilson (2).

Hybridization conditions. DNA was transferred from agarose gels to nitrocellulose for Southern blots according to the method of Smith and Summers (34) and hybridized with DNA radiolabeled with $\left[\alpha-{ }^{32} \mathrm{P}\right] \mathrm{dCTP}$ by nick translation, using $E$. coli DNA polymerase according to the method of Maniatis et al. (22). For hybridization of DNA separated by CHEF electrophoresis, agarose gels were similarly treated, transferred to Zeta-Probe nylon membranes (no. 162-0159); Bio-Rad Laboratories, Richmond, Calif.), UV cross-linked, and hybridized as described elsewhere (25).

In vitro transcription and translation. The polypeptides encoded by pCIS7 deletions and subclones were identified in an $E$. coli-derived in vitro transcription-translation system (8). The radiolabeled polypeptides were separated on 12 and
7.5\% polyacrylamide gels containing $0.1 \%$ sodium dodecyl sulfate as described by Laemmli (17). After electrophoresis, the gels were fixed, treated with Rapid Autoradiography Enhancer (Dupont, NEN), dried onto filter paper (Whatman, Inc., Clifton, N.J.), and autoradiographed at $-70^{\circ} \mathrm{C}$ by using XAR-5 film (Eastman Kodak Co., Rochester, N.Y.). Prestained molecular weight markers from Bethesda Research Laboratories were used to estimate the sizes of proteins synthesized.

CHEF electrophoresis. The CHEF apparatus was essentially as described by Chu et al. (5). A $1 \%$ agarose gel was electrophoresed in $0.5 \times \mathrm{TBE}$ buffer $(0.089 \mathrm{M}$ Tris-borate, $0.089 \mathrm{M}$ boric acid) for $40 \mathrm{~h}$ at $100 \mathrm{~V}$ with an 80 -s pulse time. Saccharomyces cerevisiae chromosomes and concatenated lambda DNA were used as standards and prepared as described previously $(31,38)$.

Assaying $\mathbf{T e t}^{\mathbf{r}}$ in $\boldsymbol{E}$. coli. LB broth was inoculated with HB101, HB101(pCIS7), or HB101(pBR322). In the last two cases, $50 \mu \mathrm{g}$ of ampicillin per $\mathrm{ml}$ was added to maintain positive selection for the plasmid. After $3 \mathrm{~h}$ of shaking at $37^{\circ} \mathrm{C}, 0.1 \mu \mathrm{g}$ of tetracycline per $\mathrm{ml}$ was added to each tube for induction, and the cultures were shaken for another $1.5 \mathrm{~h}$ at $37^{\circ} \mathrm{C}$. The cultures were then diluted and plated on LB medium with $50 \mu \mathrm{g}$ of ampicillin per $\mathrm{ml}$ (for viable cell count) or on LB medium containing $0.5,1.0,2.0,4.0,5.0$, or $10.0 \mu \mathrm{g}$ of tetracycline per $\mathrm{ml}$.

\section{RESULTS}

Isolation of plasmids pCIS7 and pCIS2. A long-term project in this laboratory is reconstruction of the origin region of the $B$. subtilis chromosome through isolation of overlapping restriction fragments. One approach we have used is to isolate DNA adjacent to the sites of transposon insertions. Plasmids pCIS7 and pCIS2 were isolated from Tet $^{\mathrm{s}} B$. subtilis $\mathrm{KS} 162$, one of a collection of strains containing Tn917 insertions in the oriC region (29), according to the procedure of Youngman et al. (45), using pTV20 and pTV21 22 integrative vectors. Restriction maps of the plasmids prepared by using SphI, PstI, EcoRI, and HindIII single and double digests of pCIS7 and pCIS2 are shown in Fig. 1. Plasmids pCIS7 and pCIS2 contain 11.5 and $2.5 \mathrm{~kb}$, respectively, of $B$. subtilis DNA. Subsequent hybridization to various restriction digests of genomic DNA with pCIS7 and pCIS2 verified that the plasmid DNA obtained from these rescues accurately represented the chromosome (data not shown).

Amplification after integration of pCIS7 induces Tet ${ }^{r}$. To confirm the chromosomal location of the DNA cloned in pCÍS7, a strain with the plasmid integrated into the chromosome [168(pCIS7)] was chosen as a donor for genetic mapping. In screening these transformants, an unexpected phenotype of $\mathrm{Tet}^{\mathrm{r}}$ was observed. Although pCIS7 had been isolated from a transposon insertion in $\mathrm{Tet}^{\mathrm{s}}$ strain $\mathrm{KS} 162$, 
transformation of $B$. subtilis 168 with pCIS7 resulted in transformants which were $\mathrm{Tet}^{\mathrm{r}}$. Although the process is inefficient, this phenotype could be assayed directly by plating transformants on TBAB medium containing tetracycline. An increase in the number of transformants recovered could be seen if a subinhibitory $(0.3 \mu \mathrm{g} / \mathrm{ml})$ concentration of tetracycline was added to the transformation sample 30 to 40 min before plating, which suggested that this resistance was inducible. However, if primary selection was made for the vector marker (on TBAB medium containing $5 \mu \mathrm{g}$ of chloramphenicol per $\mathrm{ml}$ ), many transformants were recovered; all demonstrated $\mathrm{Tet}^{\mathrm{r}}$ after 24 to $48 \mathrm{~h}$ of incubation at $37^{\circ} \mathrm{C}$ when transferred to TBAB containing tetracycline. The Tet ${ }^{r}$ transformants could be induced to high levels of resistance (up to $150 \mu \mathrm{g} / \mathrm{ml}$ ) if sequentially patched to higher levels of tetracycline. Ability to survive high levels of tetracycline was rapidly lost if cells were switched from tetracycline-containing medium to medium containing chloramphenicol.

The Tet $^{r}$ transformants were not cross-resistant to minotetracycline, erythromycin, kanamycin, or tunicamycin but were resistant to the related tetracycline analog chlortetracycline, which suggested that the resistance was not a general transport defect. We were also able to determine, by the method of Speer and Salyers (35), that tetracycline was not inactivated by these resistant strains (C. L. Ives and K. F. Bott, unpublished results).

Since previously reported $\mathrm{Tet}^{\mathrm{r}}$ determinants isolated from gram-positive organisms, including $B$. subtilis, are also functional in $E$. coli (11), pCIS7 was tested for Tet $^{r}$ in $E$. coli. Under the experimental conditions described in Materials and Methods, pCIS7 did not express Tet $^{\mathrm{r}}$ in $E$. coli.

In $E c o$ RI digests of chromosomal DNA prepared from $B$. subtilis 168 (pCIS7) transformants, amplified restriction fragments of 12 and $6.5 \mathrm{~kb}$ were visualized in agarose gels (Fig. 2). Hybridization of these chromosomal digests with pCIS7 showed that the amplified 12- and 6.5-kb EcoRI fragments corresponded to the integrated plasmid (Fig. 2B, lanes 4 through 16). B. subtilis 168 contained an 11.5-kb EcoRI fragment which hybridized to pCIS7 (Fig. 2B, lane 2). RAD1, a Tet ${ }^{r}$ strain derived from protoplasts (41), contained an amplified 11.5-kb EcoRI fragment which also hybridized to pCIS7 (Fig. 2B, lane 3). Chromosomal DNA prepared from $\mathrm{Tet}^{\mathrm{r}}$ transformants was always accompained by amplified sequences, but primary selection for Cat ${ }^{r}$ transformants did not show this amplification (data not shown), which suggested that a substantial increase in copy number of the integrated sequences is necessary for $\mathrm{Tet}^{\mathrm{r}}$. Furthermore, maintaining the isolates on higher levels of chloramphenicol did not maintain the amplification. Removal of the tetracycline selection (regardless of chloramphenicol resistance $\left[\mathrm{Cm}^{\mathrm{r}}\right]$ association) permitted loss of amplification.

Expression of Tet ${ }^{r}$ in $B$. subtilis requires amplification of DNA. The deletions and subclones constructed for in vitro transcription-translation analysis were tested for the ability to confer Tet $^{r}$ when transformed into B. subtilis 168 (Fig. 3, column 1). Primary selection on TBAB medium containing chloramphenicol was used to monitor transformants; these transformants were subsequently screened for the ability to confer Tet $^{r}$ if transferred to successively higher levels of tetracycline. Those deletions that conferred $\mathrm{Tet}^{\mathrm{r}}(\mathrm{pG} 1, \mathrm{pG} 9$, pR11, pY2, and pG4) all contained a 1.8-kb HindIII fragment consisting of $1.3 \mathrm{~kb}$ of Tn917 DNA and 800 base pairs of $B$. subtilis DNA.

In EcoRI restriction digests of chromosomal DNA prepared from 168(pG9), 168(pR11), 168(pY2), and 168(pG4), a $12-\mathrm{kb}$ and a $6.5-\mathrm{kb}$ fragment were amplified (data not shown). This is the same amplification pattern seen with 168(pCIS7) (Fig. 2, lanes 4 through 16). A proposed model for the integration and amplification of pCIS7 and deletions is shown in Fig. 4. The size of these EcoRI restriction enzyme fragments is predicted by our integration model. With this model, we would also predict an amplification of a 19-kb SfiI restriction enzyme fragment and an increase in size of a $60-\mathrm{kb}$ BamHI fragment, which was demonstrated in other experiments (data not shown). Janniere et al. described the construction of stable gene amplifications in the B. subtilis chromosome (15). For amplification to occur, a genetic marker has to be flanked by a directly repeated sequence. A single crossover event would produce a duplication of chromosomal sequences on either side of the target DNA. In our case, the deleted plasmids which conferred Tet ${ }^{\mathrm{r}}$ contained a directly repeated 1.8-kb HindIII fragment when integrated into the chromosome. The duplicated sequences could then be used for recombination and amplification of the entire 12.0-kb EcoRI restriction fragment during subsequent replication and recombination events. Plasmids pG6 and pR13 lack DNA flanking the $72 \mathrm{kDa}$ gene which is essential for generating the same type of direct repeat. We believe that this is the reason they do not confer Tet ${ }^{r}$.

The 1.8-kb HindIII fragment and three other fragments of pICS7 were subcloned and tested for the ability to confer Tet $^{\mathrm{r}}$ when integrated into the B. subtilis chromosome (Fig. 3, column 1). None of the four subclones constructed (pA25, p4-9, pY4, and p6SP) conferred $\mathrm{Tet}^{\mathrm{r}}$ on $B$. subtilis, which indicated that the DNA was not sufficient to encode the $72-\mathrm{kDa}$ protein or to confer amplification properties. Plasmids pG6 and pR13 lack DNA flanking the 72-kDa gene which is thought to be necessary for generating the same type of direct repeat. These two plasmids; when integrated into the $B$. subtilis chromosome, gave $\mathrm{Cm}^{\mathrm{r}}$ transformants but could not confer Tet $^{r}$. Synthesis of the 72-kDa gene and amplification of this DNA in B. subtilis appears necessary for expression of $\mathrm{Tet}^{\mathrm{r}}$.

Expression of a protein associated with Tet $^{r}$ in vitro. The protein products encoded by deletions and subclones of pCIS7 were examined (Fig. 3). Preliminary experiments with isolated membrane fractions of $168(\mathrm{pCIS} 7)$ provided a complex though reproducible protein-staining profile in which a $72-\mathrm{kDa}$ protein was present. An analogous band was not detected in wild-type $B$. subtilis 168 or other Tet ${ }^{\mathrm{s}}$ derivatives (Ives and Bott, unpublished results). The deletion plasmids pG1, pG4, pG6, pR11, pR13, and pY2 and subclones.p4-9, p6SP, and pY4, along with positive control pCIS7 and negative controls pTV2 0 and pGEM-BLUE, were purified on a $\mathrm{CsCl}$ gradient and introduced into a coupled $E$. coli transcription-translation system (8). Protein products, radiolabeled with $\left[{ }^{35} \mathrm{~S}\right]$ methionine, were separated on sodium dodecyl sulfate-polyacrylamide gels (Fig. 5). In addition to producing the intact $31-\mathrm{kDa} \beta$-lactamase protein and other smaller bands, pCIS7 and pY2 each produced a 72-kDa band which was absent from the other plasmids (Fig. 3, column 2). Plasmids $\mathrm{pR} 11$ and $\mathrm{p} 4-9$ each produced a truncated version of this protein of approximately $68 \mathrm{kDa}$. Plasmid pR11 also produced a protein of $64 \mathrm{kDa}$. Plasmids pG1 and pG4 produced smaller proteins of 20 and $24 \mathrm{kDa}$, respectively. The negative controls, pTV20 and pGEM-BLUE, did not synthesize any protein larger than that expressed by the $\beta$-lactamase gene, nor did pR13 or pG6. Collectively, the results suggest that a $72-\mathrm{kDa}$ protein is associated with the region of the genome that confers the $\operatorname{Tet}^{\mathrm{r}}$ phenotype. The promoter of the $72-\mathrm{kDa}$ gene appeared to lie within the cloned sequences, since both pR11 and p4-9 synthesized a 


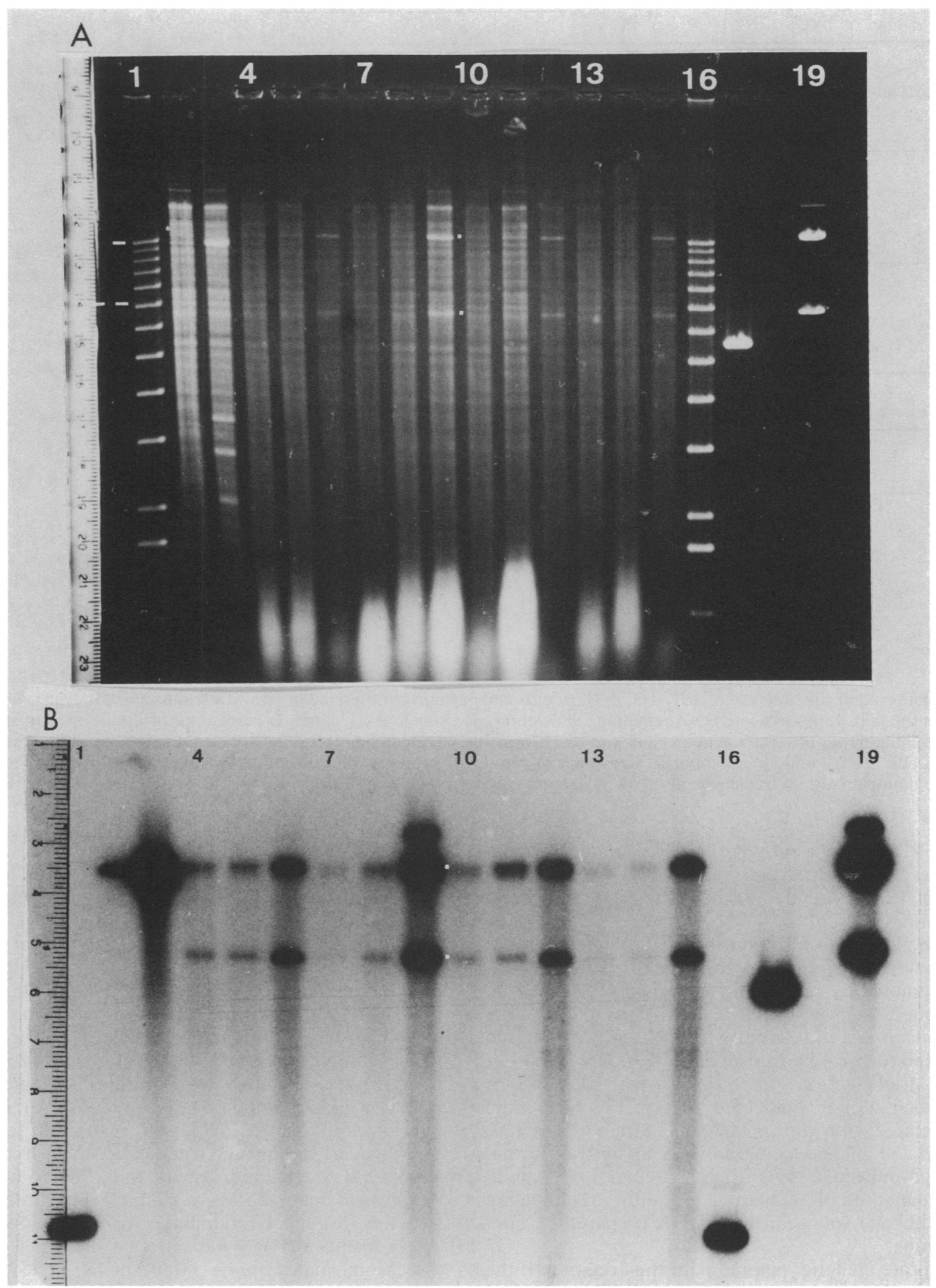

FIG. 2. Transformation of the Tet ${ }^{\mathrm{r}}$ phenotype. (A) Agarose gel electrophoresis of EcoRI digests of chromosomal DNA (3 $\left.\mu \mathrm{g} / \mathrm{ml}\right) \mathrm{prepared}$ from four separate $\mathrm{Cm}^{\mathrm{r}}$ isolates after transformation with pCIS7 and of control strains 168 and RAD1. Lanes: 1 and 16, size marker 1-kb ladder; 2, strain 168; 3, RAD1, a protoplasted $\mathrm{Tet}^{\mathrm{r}}$ regenerant; 4, 7, 10, and 13, separate $\mathrm{Cm}^{\mathrm{r}}$ transformants (selected at $5 \mu \mathrm{g}$ of chloramphenicol per $\mathrm{ml}) ; 5,8,11$, and 14 , the original transformants from lanes $4,7,10$, and 13 after passage to chloramphenicol (20 $\mu \mathrm{g} / \mathrm{ml})$; $6,9,12$, and 15 , transformants from lanes $5,8,11$, and 14 after passage to tetracycline $(20 \mu \mathrm{g} / \mathrm{ml}) ; 17$, vector alone; 19 , pCIS7 (see Table 1$)$. Marker dots between lanes 9 and 10 designate 12 and $6.5 \mathrm{~kb}$. (B) Southern blot hybridization of agarose gel from panel A probed with ${ }^{32} \mathrm{P}$-labeled pCIS7 (one fragment in the 1-kb ladder shares homology with the vector). Minor bands at $18 \mathrm{~kb}$ in lanes 9 and 19 indicate partial digest. 


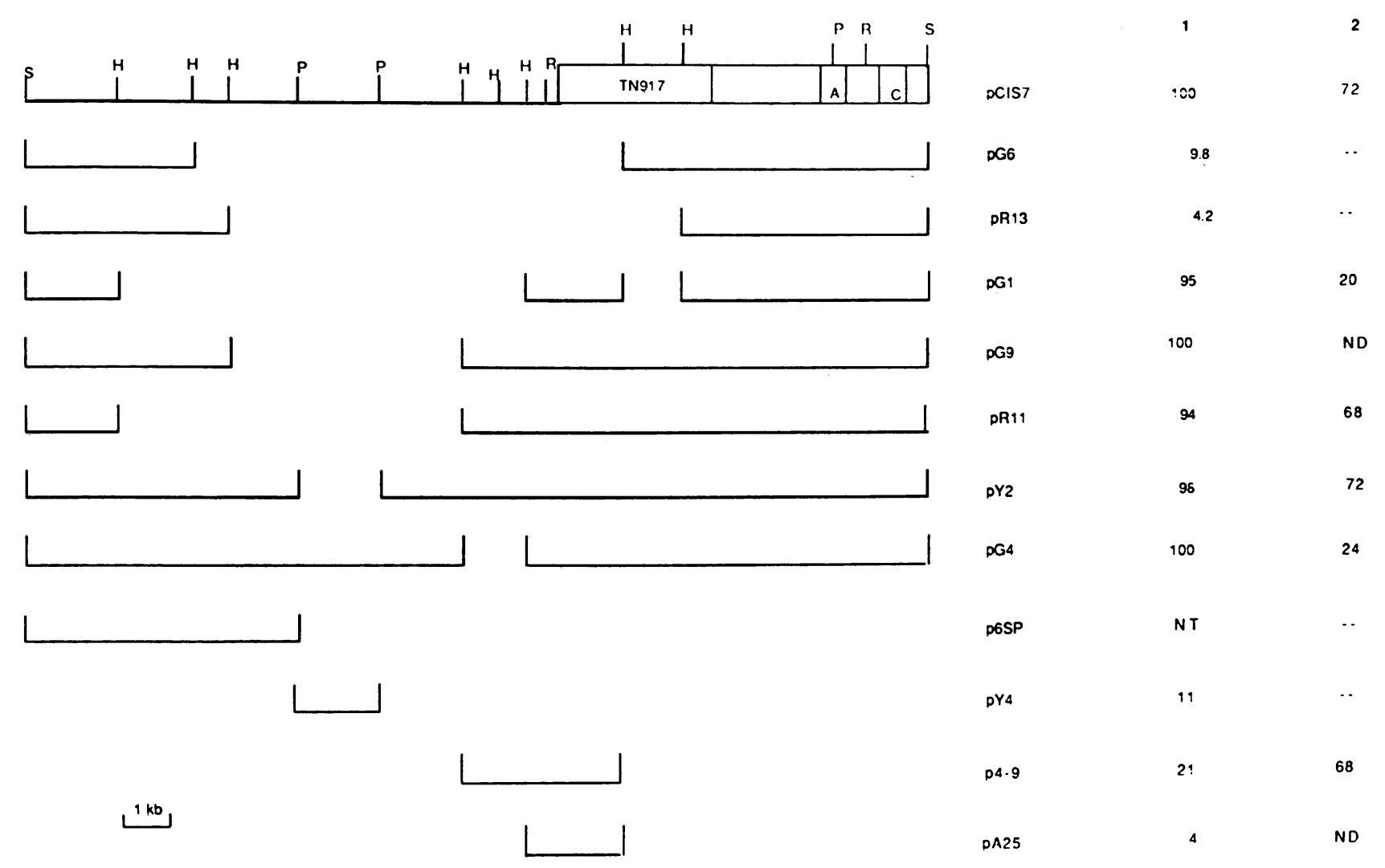

FIG. 3. Deletions and subclones of pCIS7: $\operatorname{Tet}^{\mathrm{r}}$ in $B$. subtilis and proteins synthesized in vitro. Deletions and subclones were constructed as described in the text. Lines indicate DNA remaining in deletions and subclones. Column 1: Percentage of Cat ${ }^{\mathrm{r}}$ transformants able to grow on media containing $50 \mu \mathrm{g}$ of tetracycline per ml. Cat ${ }^{\mathrm{r}}$ transformants were patched to tetracycline-containing media at sequentially higher concentrations $(10,15,20$, and 50). Column 2: Sizes (in kilodaltons) of proteins synthesized in an $E$. coli in vitro transcription-translation system. Abbreviations: NT, no transformants; ND, not done; --, no proteins synthesized; R, EcoRI; S, SphI; H, HindIII; P, PstI.

truncated $68-\mathrm{kDa}$ protein but were in different vector backgrounds. These results suggest that the 3.1-kb PstI-EcoRI fragment of pCIS7 is essential for the expression of a protein associated with Tet ${ }^{\mathrm{r}}$.

Genetic and physical localization of pCIS7. As mentioned at the outset, our original aim was to isolate $B$. subtilis chromosomal fragments encompassing the origin of replication. We thus wished to map the DNA carried by pCIS7. The initial transposon insertion from which pCIS7 was excised was $42 \%$ linked to guaA by transduction (29). However, our preliminary transduction analysis, using $B$. subtilis 168(pCIS7) as a donor, indicated that pCIS7 was more closely associated with the purA locus. Strain 168(pCIS7) demonstrated $7 \%$ linkage to the purA locus by transformation using high-molecular-weight DNA prepared by a modification of the method of Schwartz and Cantor (31) (data not shown). No linkage was seen with DNA prepared by conventional means.

Since accurate genetic mapping in this region of the chromosome is difficult $(36,42)$, localizing pCIS 7 by physical linkage with other characterized clones of DNA would substantiate the proposed order of the genetic markers and eliminate the need for three-factor crosses, which at best give ambiguous results in this region of the chromosome. To this end, we used pCIS7 as a probe against a lambda Charon 30 library and isolated a recombinant phage, F3. Through hybridization analysis, phage $\mathrm{F} 3$ was shown to partially overlap pMS31, a subclone of phage 529 characterized by Sargent and Bennett (30). Phage 529 maps near purA and binds the membrane. Membrane-binding studies using independently isolated DNA from this region have recently confirmed the linear restriction map of these clones $(\mathbf{N}$. Sueoka, personal communication).

Using CHEF electrophoresis (5), we have been able to determine the orientation of this cluster of cloned DNA to other origin markers. Plasmid pCIS7 contains an SfII restriction site within the $6.0-\mathrm{kb} S p h \mathrm{I}-P$ st I restriction fragment and hybridizes to a $250-\mathrm{kb}$ and a $150-\mathrm{kb} S f i \mathrm{I}$ restriction fragment in an SfI chromosomal digest of $B$. subtilis 168 ; it also hybridizes to a 200-kb NotI restriction fragment. Plasmid pAK 1 , a clone containing the gyrA and gyrB genes (16), hybridizes to a single $250-\mathrm{kb} S$ fiI restriction fragment and a 200-kb NotI fragment, whereas pMS31 hybridizes to a $150-\mathrm{kb} S$ fiI restriction fragment and a $200-\mathrm{kb}$ Not I fragment. A physical map of this region of the chromosome constructed through overlapping clones is shown in Fig. 6. These results strongly indicate that the order of markers in the chromosome is purA-pMS31-pCIS7-pCIS2-pAK1(Nov)guaA and expand the physical characterization of the chromosome in this region.

\section{DISCUSSION}

Isolation of pCIS7 by excision of DNA adjacent to Tn917 insertions has led to a more complete characterization of the origin region of $B$. subtilis. We have now linked four clones comprising $30 \mathrm{~kb}$ of contiguous DNA from this region. Through CHEF electrophoresis, these clones have been 


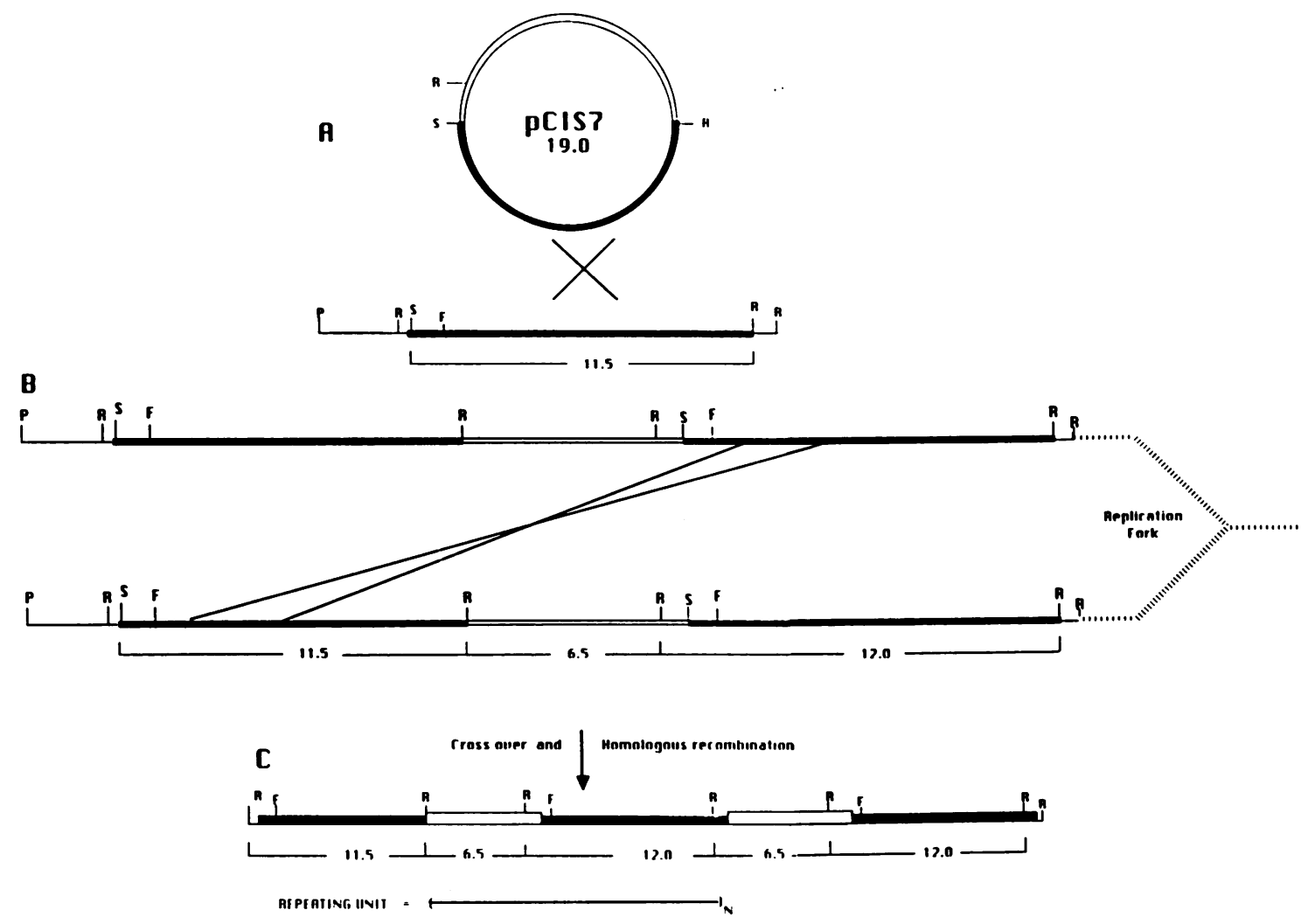

FIG. 4. Proposed model of integration and amplification of pCIS7 into the $B$. subtilis chromosome. (A) pCIS7 integrating into the $B$. subtilis chromosome by a single crossover event; (B) outcome of such an integration, with duplicated chromosomal DNA flanking vector sequences; (C) amplification of the duplicated sequences in panel B by crossover between nascent daughter chromosomes. The expected amplified EcoRI restriction fragments are given. Open boxes indicate vector sequences. Black boxes show cloned chromosomal sequences. Thin lines flanking the black boxes depict chromosomal DNA adjacent to the cloned fragment. Abbreviations: R, EcoRI; S, SphI; F, SfiI.

placed on a single NotI restriction fragment and two Sfi fragments encompassing $400 \mathrm{~kb}$ of DNA, providing an accurate physical map of the origin region where many genetic anomalies have been described.

Amplification of a component within pCIS7 was required for expression of $\mathrm{Tet}^{\mathrm{r}}$. This was demonstrated by deletion analysis, in which those plasmids which conferred $\operatorname{Tet}^{\mathrm{r}}$ upon transformation and integration into the chromosome contained DNA which gave rise to a direct repeat flanking the 72-kDa gene. The deletion plasmids themselves did not need to contain the $72-\mathrm{kDa}$ gene, because this DNA was regenerated from the single intact copy already present in the chromosome, provided that a direct repeat flanking the gene was present. Theoretically, this flanking DNA (the $1.8-\mathrm{kb}$ HindIII fragment) served as a bridge between replicating sister chromatids during DNA replication, regenerating the complete 12-kb EcoRI fragment seen in chromosomal digests of these integrated strains. An alteration in the $6.5-\mathrm{kb}$ EcoRI fragment was seen in pG1, but this was due to deletion of vector DNA. The 12-kb EcoRI fragment was still regenerated and amplified.

The numer of copies necessary to confer $\operatorname{Tet}^{r}$ is not known but is almost certainly more than 20 per chromosome. Young has shown that plasmid DNA integrated into the $B$. subtilis chromosome can be amplified 15-fold when selection is increased from 5 to $20 \mu \mathrm{g}$ of chloramphenicol per $\mathrm{ml}$ (44). In our case, this amount of amplification did not significantly alter the intensity of restriction fragments in a chromosomal digest (Fig. 2B). Transfer of 168(pCIS7) from $20 \mu \mathrm{g}$ of chloramphenicol per $\mathrm{ml}$ to tetracycline resulted in a dramatic

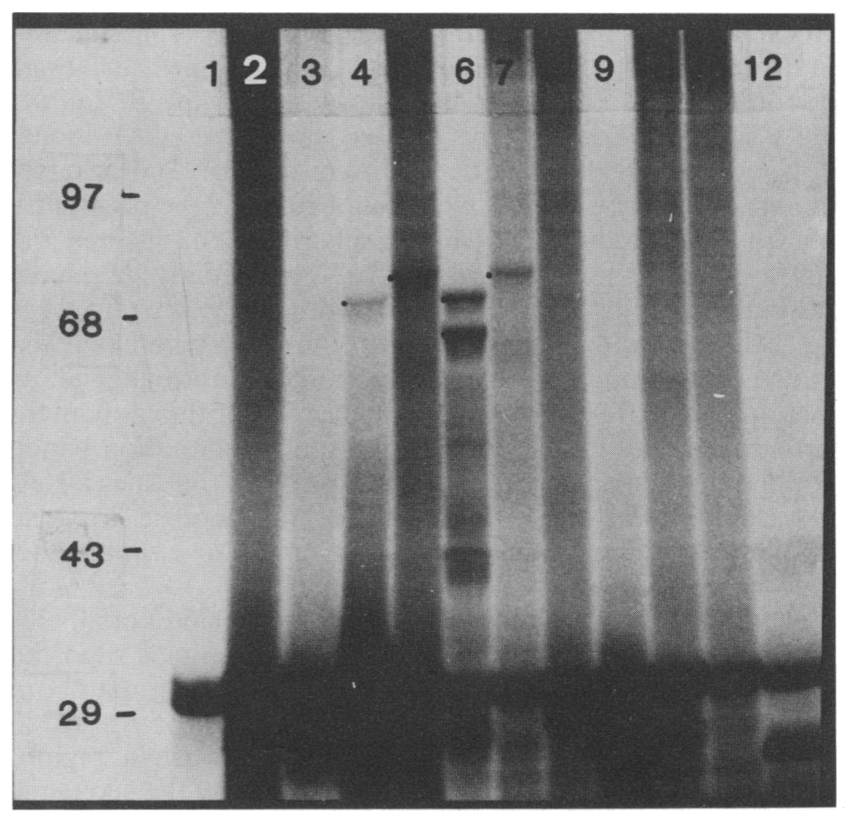

FIG. 5. In vitro transcription-translation analysis of pCIS7 deletions and subclones. In vitro transcription-translation products derived from pGEM-BLUE, p6SP, pY4, p4-9, pCIS7, pR11, pY2, pG4, pG1, pG6, pR13, and pTV20 (lanes 1 through 12). Molecular size markers on the left are expressed in kilodaltons. 

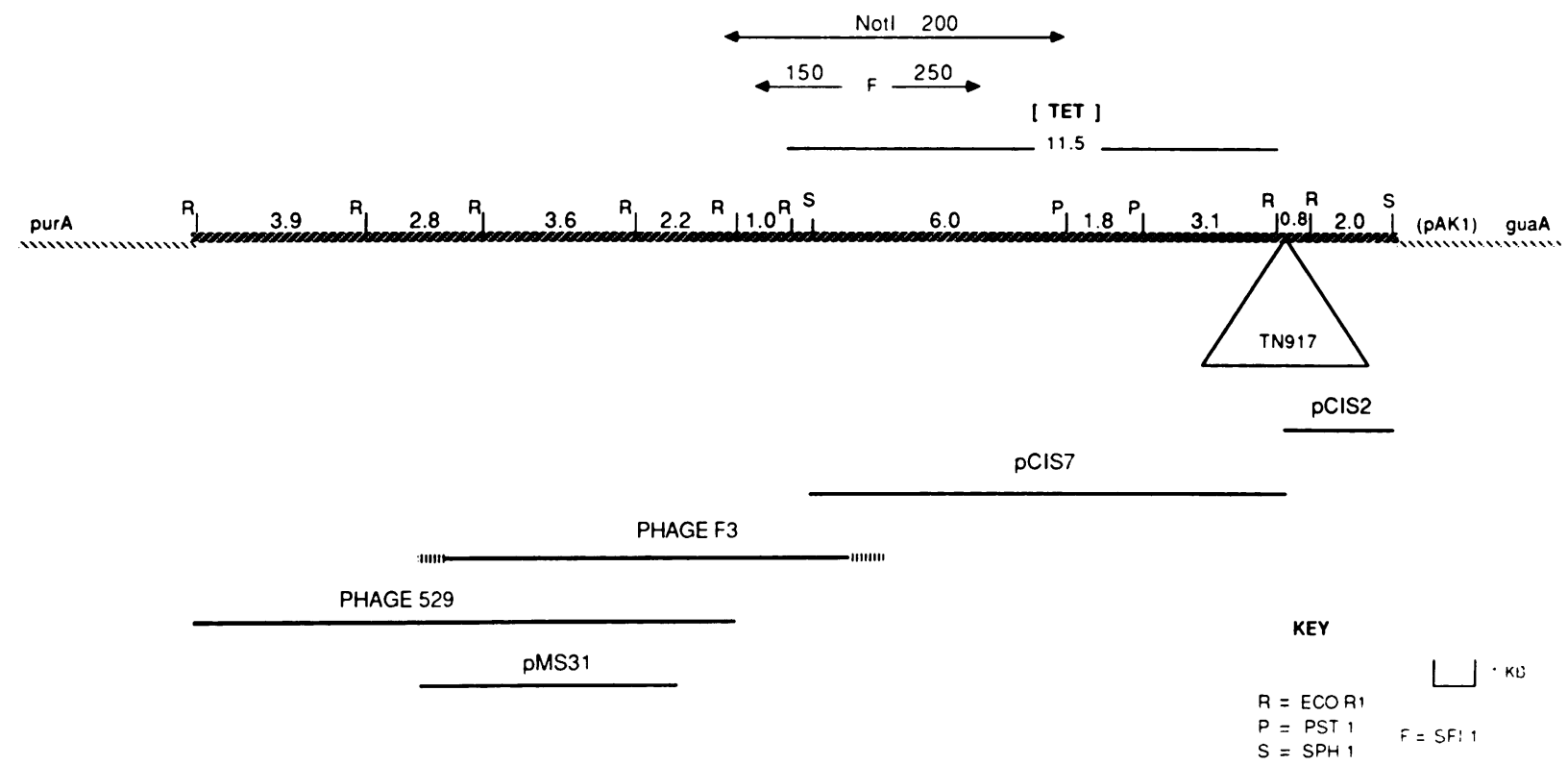

FIG. 6. Restriction map of the purA region of the B. subtilis chromosome. Cloned chromosomal DNA (hatched line) showing orientation to purA, pAK1, and guaA, with clones indicated underneath. Double lines on phage F3 indicate uncertainty of endpoints of cloned DNA. The $E c o$ RI fragment believed to be required for $\mathrm{Tet}^{\mathrm{r}}$ is indicated at the top (see text for details). Numbers above arrows indicate sizes of $S f \mathrm{I}$ fragments in the chromosome. Plasmids pCIS7 and pCIS2 were cloned from the Tn917 insertion.

increase in intensity of EcoRI fragments in a chromosomal digest, which indicated that more than 15 copies of integrated plasmid was needed for $\mathrm{Tet}^{\mathrm{r}}$. When 168(pCIS7) was passaged from TBAB containing tetracycline back to TBAB containing $20 \mu \mathrm{g}$ of chloramphenicol per $\mathrm{ml}$, this intense banding was lost (Ives and Bott, unpublished observations).

Although the four chromosomal $\mathrm{Tet}^{\mathrm{r}}$ determinants reported in $B$. subtilis share some properties, there are differences. The tet $B$ determinant characterized by Williams and Smith (40) is reported to map between the guaA and cys $A$ loci on the $B$. subtilis chromosome, whereas the $B$. subtilis DNA in pCIS7 is clearly located near the purA locus. However, since the genetic mapping data are notoriously inconsistent in this region, we cannot rule out the possibility that the tetB locus was imprecisely mapped, just as the Tn917 insertion in $B$. subtilis KS162 was initially. We have been unable to detect amplified DNA in the tetB strain (Ives and Bott, unpublished results). It is unclear whether resistance is determined by overproduction of a normal gene, as postulated for 168 (pCIS7). The phenotype of this nonamplified strain could be ascribed to a promoter mutation which would cause an increase in transcription in this DNA, essentially mimicking the effect of an increase in gene dosage. However, experimental evidence to support this hypothesis is currently lacking.

The Tet ${ }^{r}$ determinant characterized by Shishido et al. (33) (pNS1981) also differs from the $\mathrm{Tet}^{\mathrm{r}}$ determinant reported here. Unfortunately, there is no genetic mapping data concerning the location of the $\mathrm{Tet}^{\mathrm{r}}$ determinant of $\mathrm{pNS1981}$, so it is not known whether it arose from the origin region. Sakaguchi and Shishido have recently reported the sequence homology between fragments from the chromosome of several $B$. subtilis isolates which confer $\mathrm{Tet}^{\mathrm{r}}$ when cloned on a multicopy plasmid vector $(27,28)$. Although these plasmids were Tet $^{\mathrm{r}}$ in $E$. coli (in a range of 30 to $80 \mu \mathrm{g} / \mathrm{ml}$ ), we were unable to show $\operatorname{Tet}^{\mathrm{r}}$ of pCIS7 in $E$. coli by using similar procedures. However, it must be noted that our experiments were all conducted under the assumption that the pBR322 replicon bearing these test fragments would have been capable of sufficient amplification to elicit $\operatorname{Tet}^{r}$ if it could be produced. We did not quantitate the copy number of the vector and our test plasmids but assumed that it would be different from the copy number of the normal pBR322 replicon. Plasmid pNS1981 is nearly identical to pBC16 (32); hybridization analysis using $\mathrm{pBC} 16$ as a probe demonstrated homology between this plasmid and pCIS7 only at low stringency (Ives and Bott, unpublished observations). The Tet $^{\mathrm{r}}$ gene of $\mathrm{pBC} 16$ has been sequenced and is estimated to encode a protein of $50 \mathrm{kDa}(33)$, whereas in vitro transcription-translation data suggest that the $\mathrm{Tet}^{\mathrm{r}}$ determinant of pCIS7 is $72 \mathrm{kDa}$. Another gram-positive Tet ${ }^{\mathrm{r}}$ determinant, tet $O$, was recently sequenced by LeBlanc et al. (19) and encodes a $72-\mathrm{kDa}$ protein. Preliminary sequence analysis between tetO and DNA fragments of pCIS7 have not demonstrated any sequence homology (Ives and Bott, unpublished results).

The endogenous gene amplifications associated with Tet $^{r}$ described by Wilson and Morgan (41) do appear to involve the same DNA as do Tet $^{r}$ 168(pCIS7) transformants, since pCIS7 hybridizes to an 11.5-kb EcoRI chromosomal fragment in these strains. However, DNA from these protoplasted strains has not been cloned or physically characterized. Since restriction enzyme digest patterns, function in $E$. coli, cross-hybridization with other Bacillus-derived $\mathrm{Tet}^{\mathrm{r}}$ determinants, and predicted size of protein associated with the $\operatorname{Tet}^{\mathrm{r}}$ phenotype $(28,32)$ all differ considerably, there may be multiple chromosomal fragments capable of eliciting this phenotype.

Collectively, these results suggest that more than one locus on the $B$. subtilis chromosome can be altered to confer $\mathrm{Tet}^{\mathrm{r}}$ or that analogous regions on the chromosome of various B. subtilis strains confer $\mathrm{Tet}^{\mathrm{r}}$ differently. 


\section{ACKNOWLEDGMENTS}

We thank Patrick Piggot for pMS31 and advice on CHEF electrophoresis, Dan Loeb and Rick Padgett for construction of the Charon 30 lambda library, and Mary Lampe for pMI1101. We thank the Dow Chemical Co. and Ron Wilson (currently at Henkle Corp.) for the RAD1 strain and helpful discussions. We gratefully acknowledge Judith B. Weiss for assistance and advice on the in vitro transcription-translation analysis and Janne Cannon, Priscilla Wyrick, Howard Fried, S. B. Levy, and P. Fredrick Sparling for valuable discussions.

\section{LITERATURE CITED}

1. Bernhard, K., H. Schrempf, and W. Goebel. 1978. Bacteriocin and antibiotic resistance plasmids in Bacillus cereus and Bacillus subtilis. J. Bacteriol. 133:897-903.

2. Bott, K. F., and G. A. Wilson. 1968. Metabolic and nutritional factors influencing the development of competence for transfection of Bacillus subtilis. Bacteriol. Rev. 32:370-378.

3. Burdett, V. 1986. Streptococcal tetracycline resistance mediated at the level of protein synthesis. J. Bacteriol. 165:564-569.

4. Chopra, I., and T. G. B. Howe. 1978. Bacterial resistance to the tetracyclines. Microbiol. Rev. 42:707-724.

5. Chu, G., D. Vollrath, and R. W. Davis. 1986. Separation of large DNA molecules by contour-clamped homogeneous electric fields. Science 234:1582-1585.

6. Clewell, D. B., Y. Yagi, and B. Bauer. 1975. Plasmid determined tetracycline resistance in Streptococcus faecalis: evidence for gene amplification during growth in the presence of tetracycline. Proc. Natl. Acad. Sci. USA 72:1720-1724.

7. Dedonder, R. A., J.-A. Lepesant, J. Lepesant-Kejzlarova, A. Billault, M. Steinmetz, and F. Kunst. 1977. Construction of a kit of reference strains for rapid genetic mapping in Bacillus subtilis 168. Appl. Environ. Microbiol. 33:989-993.

8. DeVries, J. K., and G. Zubay. 1967. DNA-directed peptide synthesis. II. The synthesis of the alpha-fragment of the enzyme beta-galactosidase. Proc. Natl. Acad. Sci. USA 57:1010-1012.

9. Donovan, W., L. Zheng, K. Sandman, and R. Losick. 1987. Genes encoding spore coat polypeptides from Bacillus subtilis. J. Mol. Biol. 196:1-10.

10. Dunny, G. M., and D. B. Clewell. 1975. Transmissible toxin (hemolysin) plasmid in Streptococcus faecalis and its mobilization of a noninfectious drug resistance plasmid. J. Bacteriol. 124:784-790.

11. Eccles, S., A. Docherty, I. Chopra, S. Shales, and P. Ball. 1981. Tetracycline resistance genes from Bacillus plasmid pAB124 confer decreased accumulation of the antibiotic in Bacillus subtilis but not in Escherichia coli. J. Bacteriol. 145:1417-1420.

12. Hanahan, D. 1983. Studies on transformation of Escherichia coli with plasmids. J. Mol. Biol. 166:557-580.

13. Hoch, J. A., M. Barat, and C. Anagnostopoulos. 1967. Transformation and transduction in recombination-defective mutants of Bacillus subtilis. J. Bacteriol. 93:1925-1937.

14. Holmes, D. S., and M. Quigley. 1981. A rapid boiling method for the preparation of bacterial plasmids. Anal. Biochem. 114: 193-197.

15. Janniere, L., B. Niaudet, E. Pierre, and S. D. Ehrlich. 1985. Stable gene amplification in the chromosome of Bacillus subtilis. Gene 40:47-55.

16. Klock, G., B. Unger, C. Gataz, W. Hillen, J. Altenbuchner, K. Schmid, and R. Schmitt. 1985. Heterologous repressor-operator recognition among four tetracycline resistance determinants. J. Bacteriol. 161:326-332.

17. Laemmli, U. K. 1970 . Cleavage of structural proteins during the assembly of the head of bacteriophage T4. Nature (London) 227:680-685.

18. Lampe, M. L., and K. F. Bott. 1985. Genetic and physical organization of the cloned gyrA and gyrB genes for Bacillus subtilis. J. Bacteriol. 162:78-84.

19. LeBlanc, D. J., L. N. Lee, B. M. Titman, D. J. Smith, and F. C. Tenover. 1988. Nucleotide sequence analysis of tetracycline resistance gene tetO from Streptococcus mutans DL5. J. Bac- teriol. 170:3618-3626.

20. Levy, S. B. 1984. Resistance to tetracyclines, p. 191-240. In L. Bryan (ed.), Antimicrobials. Academic Press, Inc., Orlando, Fla.

21. Levy, S. B. 1988. Tetracycline resistance determinants are widespread. ASM News 54:418-421.

22. Maniatis, R., E. F. Fritsch, and J. Sambrook. 1982. Molecular cloning: a laboratory manual. Cold Spring Harbor Laboratory, Cold Spring Harbor, N.Y.

23. Norgard, M. V. 1981. Rapid and simple removal of contaminating RNA from plasmid DNA without the use of RNase. Anal. Biochem. 113:34-42.

24. Part, B. H., M. Hendricks, M. H. Malamy, F. P. Tally, and S. B. Levy. 1987. Cryptic tetracycline resistance determinant (class F) from Bacteroides fragilis mediates resistance in Escherichia coli by actively reducing tetracycline accumulation. Antimicrob. Agents Chemother. 31:1739-1743.

25. Reed, K. C., and D. A. Mann. 1985. Rapid transfer of DNA from agarose gels to nylon membranes. Nucleic Acids Res. 13: 7207-7221.

26. Saito, H., and K. Miura. 1963. Preparation of transforming deoxyribonucleic acid by phenol treatment. Biochim. Biophys. Acta 72:619-629.

27. Sakaguchi, R., H. Amano, and K. Shishido. 1988. Nucleotide sequence homology of the tetracycline-resistance determinant naturally maintained in $B$. subtilis Marburg 168 chromosome and the tetracycline-resistance gene of $B$. subtilis plasmid pNS1981. Biochim. Biophys. Acta 950:441-444.

28. Sakaguchi, R., and K. Shishido. 1988. Molecular cloning of a tetracycline-resistance determinant from Bacillus subtilis chromosomal DNA and its expression in Escherichia coli and $B$. subtilis. Biochim. Biophys. Acta 949:49-57.

29. Sandman, K., R. Losick, and P. Youngman. Genetic analysis of Bacillus subtilis spo mutations generated by $\mathrm{Tn} 917$-mediated insertional mutagensis. Genetics 117:603-617.

30. Sargent, M. G., and M. F. Bennett. 1985. Amplification of a major membrane-bound DNA sequence of Bacillus subtilis. J. Bacteriol. 161:589-595.

31. Schwartz, D. C., and C. R. Cantor. 1984. Separation of yeast chromosome sized DNA's by pulsed field gradient gel electrophoresis. Cell 37:67-75.

32. Shishido, K., N. Noguchi, N. C. Kim, and T. Ando. 1983 Isolation of a tetracycline resistance plasmid excised from a chromosomal DNA sequence in Bacillus subtilis. Plasmid 10: 224-234.

33. Shishido, K., R. Sakaguchi, N. Noguchi, and M. Kono. 1987. High degree of homology of the deduced protein structures of the tetracycline-resistance determinants between Bacillus subtilis plasmid pNS1981 and Staphylococcus aureus plasmid pTP5. J. Protein Chem. 6:473-478.

34. Smith, G. E., and M. D. Summers. 1980. The bidirectional transfer of DNA and RNA to nitrocellulose or diazobenzyloxymethyl paper. Anal. Biochem. 109:123-129.

35. Speer, B. S., and A. A. Salyers. 1988. Characterization of a novel tetracycline resistance that functions only in aerobically grown Escherichia coli. J. Bacteriol.170:1423-1429.

35a.Sougakoff, W., B. Papadopoulou, P. Nordmann, and P. Courvalin. 1987. Nucleotide sequence and distribution of gene tetO encoding tetracycline resistance in Campylobacter coli. FEMS Microbiol. Lett. 44:153-160.

36. Sugino, A., and K. Bott. 1980. Bacillus subtilis deoxyribonucleic acid gyrase. J. Bacteriol. 141:1331-1339.

37. Takahashi, I. 1963. Transducing phages for Bacillus subtilis. J. Gen. Microbiol. 31:211-217.

38. Waterbury, P. G., and M. J. Lane. 1987. Generation of lambda phage concatemers for use as pulsed field electrophoresis size markers. Nucleic Acids Res. 15:3930.

39. Waters, S. H., P. Regowsky, J. Grinsted, J. Altenbuchner, and R. Schmitt. 1984. The tetracycline resistance determinants of RP1 and Tn1721: nucleotide sequence analysis. Nucleic Acids Res. 11:6089-6105.

40. Williams, G., and I. Smith. 1979. Chromosomal mutations 
causing resistance to tetracycline in Bacillus subtilis. Mol. Gen. Genet. 177:23-29.

41. Wilson, C. R., and A. E. Morgan. 1985. Chromosomal DNA amplification in Bacillus subtilis. J. Bacteriol. 163:445-453.

42. Wilson, F. E., J. A. Hoch, and K. Bott. 1981. Genetic mapping of a linked cluster of ribosomal ribonucleic acid genes in Bacillus subtilis. J. Bacteriol. 148:624-628.

43. Yang, H. L., G. Zubay, and S. B. Levy. 1976. Synthesis of an R plasmid protein associated with tetracycline resistance is negatively regulated. Proc. Natl. Acad. Sci. USA 73:1509-1512.

44. Young, M. 1985. Gene amplification in Bacillus subtilis. J. Gen. Microbiol. 130:1613-1621.

45. Youngman, P., J. B. Perkins, and R. Losick. 1984. A novel method for the rapid cloning in Escherichia coli of Bacillus subtilis chromosomal DNA adjacent to Tn917 insertions. Mol. Gen. Genet. 195:424-433. 